\title{
Changes in the structure of the heart and blood pressure after a period of concurrent endurance-resistance training in patients with chronic heart failure
}

\author{
Zahra Mahmoodi ${ }^{1}$, Ramin Shabani ${ }^{2}$, Zahra Hojjati Zidashti ${ }^{2}$, Mahboubeh Gholipour ${ }^{3}$ \\ ${ }^{1}$ PhD Candidate of Exercise Physiology, Faculty of Humanities, Department of Physical Education and sport sciences, \\ Rasht Branch, Islamic Azad University, Rasht, Iran \\ ${ }^{2}$ Associate Professor, Faculty of Humanities, Department of Physical Education and sport sciences, Rasht Branch, \\ Islamic Azad University, Rasht, Iran \\ ${ }^{3}$ Assistant Professor, Cardiovascular Diseases Research Center, Department of Cardiology, Dr Heshmat Hospital, \\ Guilan University of Medical Sciences, Rasht, Iran
}

\begin{abstract}
Background: Exercise improves functional capacity by improving endothelial function and musculoskeletal aerobic metabolism, but its effects on hemodynamic control are not well known. The aim of this study was to investigate the effect of aerobic and resistance trainings on structural changes and blood pressure in patients with heart failure.

Materials and methods: 76 patients aged 65 to 79 years with $E F \leq 40 \%$ were divided into two groups of training and control. The training group exercised endurance and resistance training for 8 weeks, three times a week for 45-60 minutes in hospital and had walking program for 4 days a week at home. Echocardiography and blood pressure indicators were measured before and after exercise. Data analysis were done using SPSS software at a significant level of 0.05 .

Results: Intra-group analysis of the experimental group by paired t-test and Wilcoxon tests showed a significant increase in LV ejection fraction and decreased end systolic and diastolic volume, diastolic interventricular septum and end diastolic and systolic diameters $(\mathrm{p}<0.05)$, and no changes in posterior wall thickness, and systolic and diastolic blood pressure $(p>0.05)$. There were no significant changes in the control group in all the variables ( $\mathrm{p}>0.05)$.

Conclusion: According to the results, it seems that concurrent endurance and resistance training improves the structure and function of the heart in patients with chronic heart failure.

Keywords: Heart failure, Systolic- endurance training, Resistance training, Concurrent training, Left ventricular ejection fraction.

Cited as: Mahmoodi Z, Shabani R, Hojjati zidashti Z, Gholipour M. Changes in the structure of the heart and blood pressure after a period of concurrent endurance-resistance training in patients with chronic heart failure. Medical Science Journal of Islamic Azad University, Tehran Medical Branch 2020; 30(3): 267-276.
\end{abstract}

Correspondence to: Ramin Shabani

Tel: +98 9112324796

E-mail: dr.ramin.shabani@gmail.com

ORCID ID: 0000-0002-2681-3814

Received: 13 Apr 2019; Accepted: 25 Agu 2019 
مجله علوم يزشكى دانشكاه آزاد اسلامى

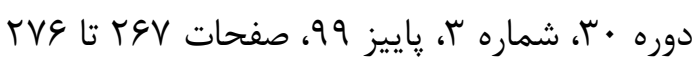

\title{
تغييرات ساختار قلب و فشار خون یس از يك دوره تمرين استقامتى - مقاومتى همزمان در بيماران مبتلا به نارسايى مزمن قلبى(CHF)
}

\author{
زهرا محمودى'؛ رامين شعبانى ‘ زهرا حجتى ‘، محبوبه قلى يور
}

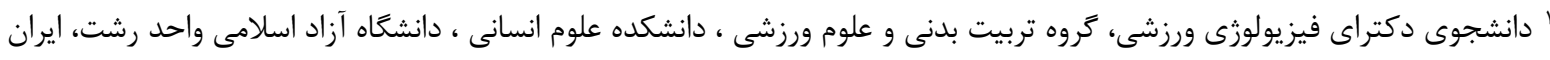

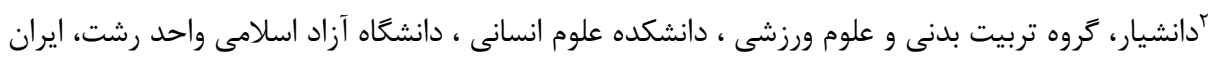

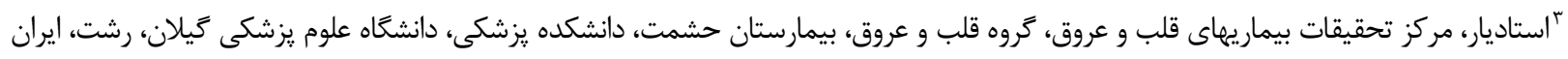
جـكيده

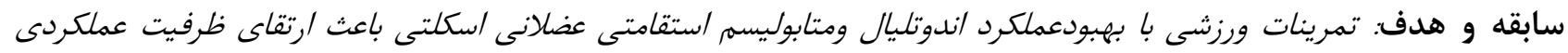

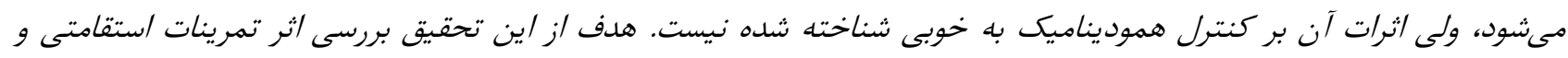

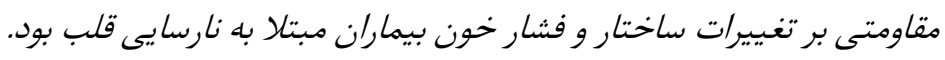

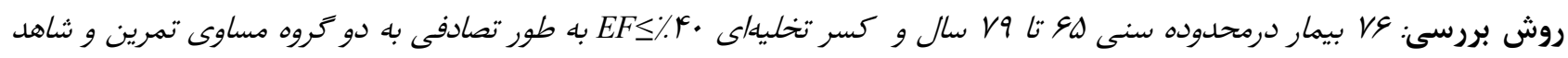

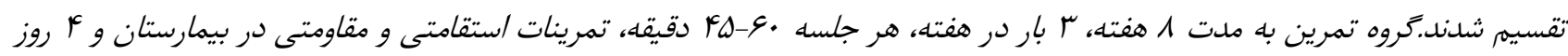

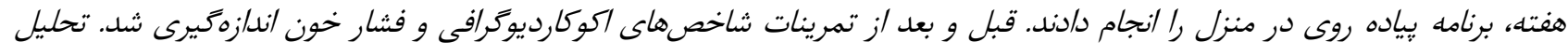

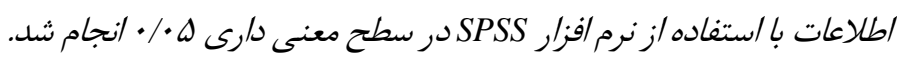

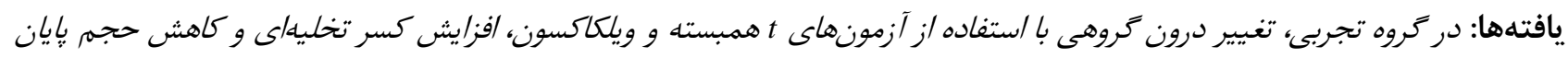

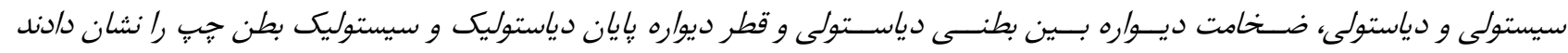

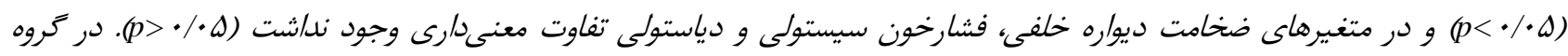

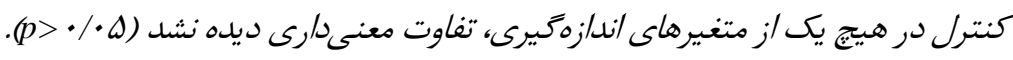

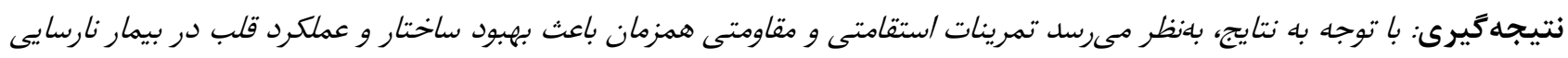
مزمن قلب مىشون. وازَكان كليدى: نارسايى مزمن قلب، تمرينات /ستقامتى - مقاومتى همزمان - كسر تزريقى.

جريان خون جهت برآوردن احتياجات متابوليك بافتهـا واعضـاى مقلدمه

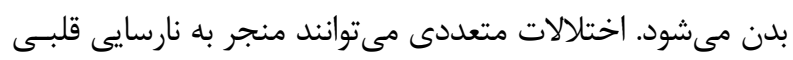

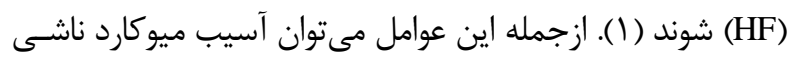

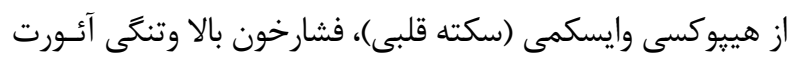

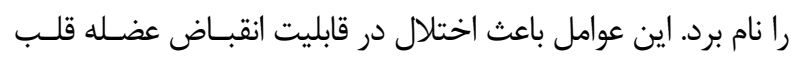

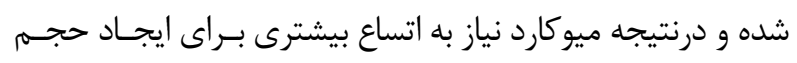

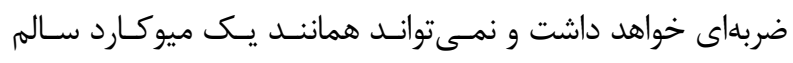

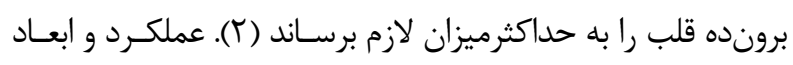
بطن جֶ (LV) معمولا توسط اكوكارديوكرافى و با محاسبه كسـر

نارسايى قلبى(Heart failure) سندرم بالينى است كـهـ بــا اخـتلال

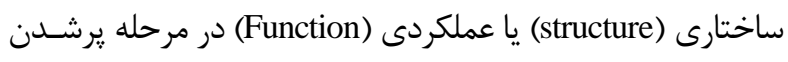

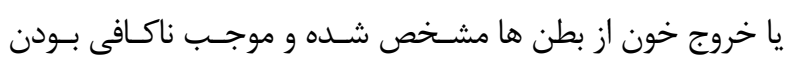

آدرس نويسنده مسئول: رشت، كروه تربيت بلدنى و علوم ورزشى ، دانشكده علوم انسـانى ، دانشـاه آزاد

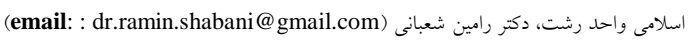
ORCID ID: 0000-0002-2681-3814 تاريخ دريافت مقاله: تارئ

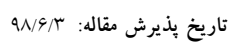


برونكرا)؛ هــدف تمـرين (تمـرين عمـومى بــن در مقابـل تمـرين

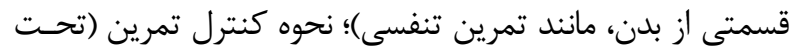

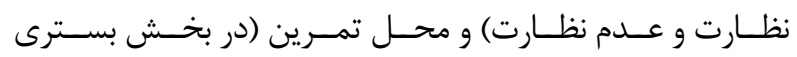
بيمارستان، سريايى، در منزل) اشاره كرد (• (1).

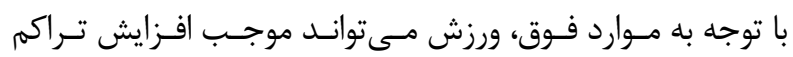

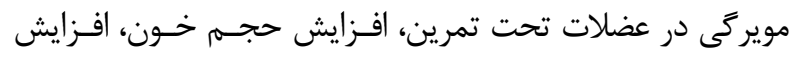

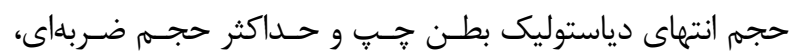
منجر به سازگارى در سيستم قلبى عروقى گردد. به اين ترتيـب در در

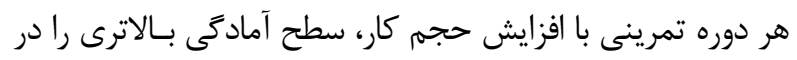

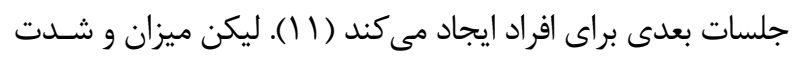
تمرينات و همجنين انتخاب بهترين شيوه براى بيماران هنوز مورد برد

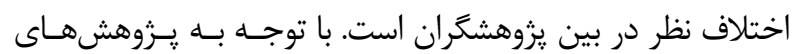

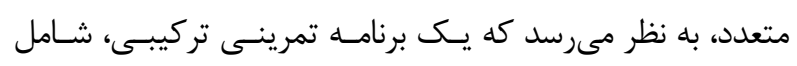

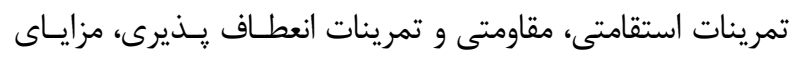

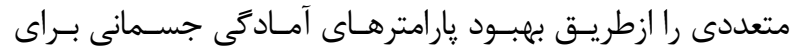

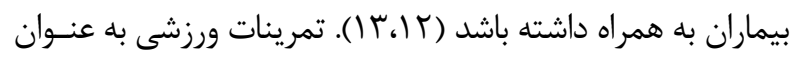

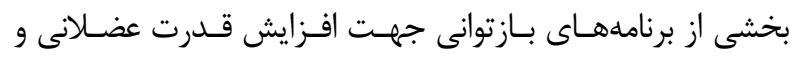

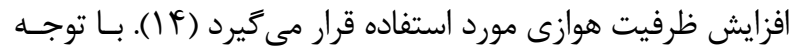

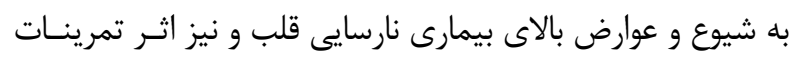

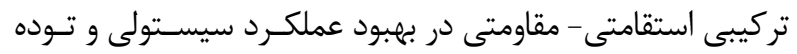
بطن جٍ و عملكرد عروقى، ضرورت دارد كه جنـين مطالعـاتى در

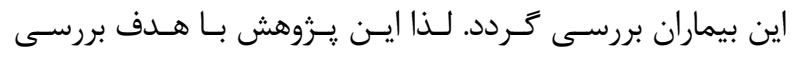

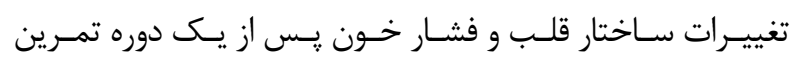

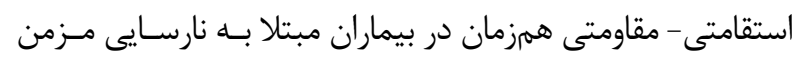

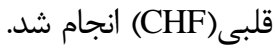

\section{مواد و روشهها - مواد}

هدف اصلى اين تحقيق بررسى اثر تمرينات استقامتى - مقـاومتى

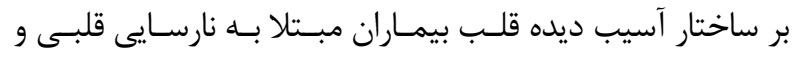

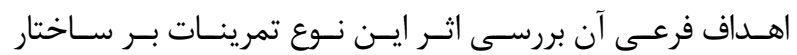

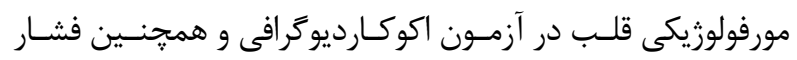

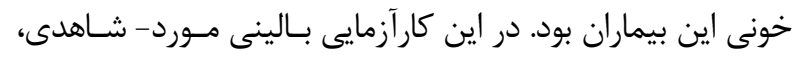

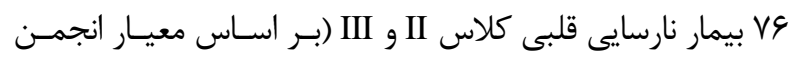
قلب نيويـورك The New York Heart Association) بـهـ صـورت داوطلبانه شركت كردند. تشخيص نوع و شدت بيمـارى بــه همــراه

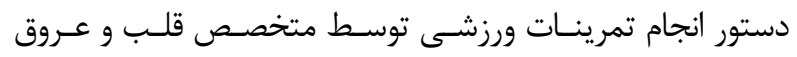

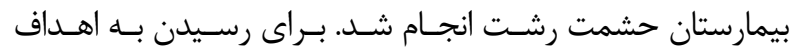

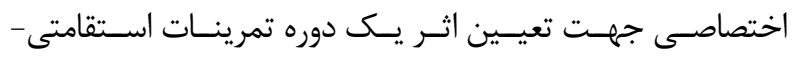

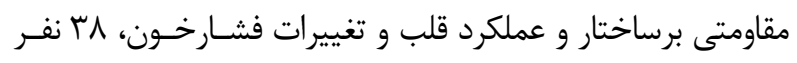

تخليهاى بطن جــ مىشود كه انواع اختلالات قلبى(نظير اختلال ميوكارد ، دريجه يـا يريكارد) را شناسايى مىنمايـد. مرحلـه اول در تشـخيص اخـتلال

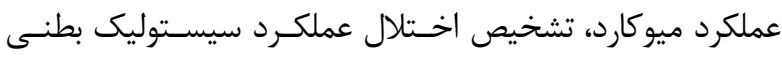
است و شايعترين روش بيان عملكرد بطن جــٍ توسـط محاسـبه

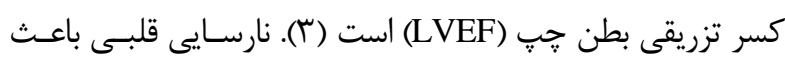

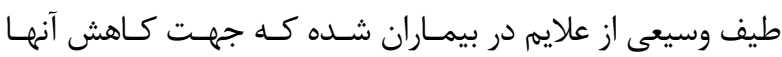

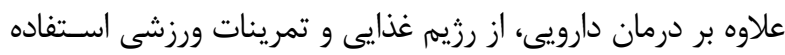

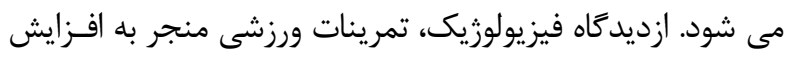

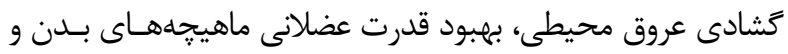

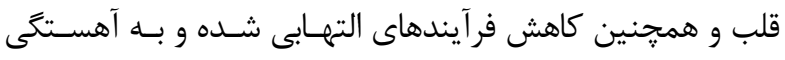
موجب بازسازى بطن جِ

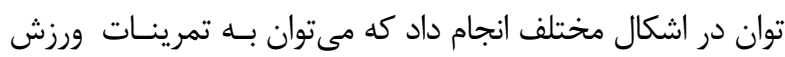
استقامتى (Endurance training) كه بر تقويـت سيسـتم قلبـى و

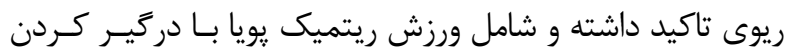

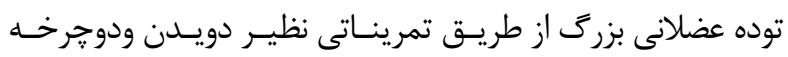
سوارى است و يا تمرينـات مقــاومتى (Resistance Exercise) كـهـ بر عملكرد دسته عضلات متكى بوده كه در آن از تمرين با وزنسه و

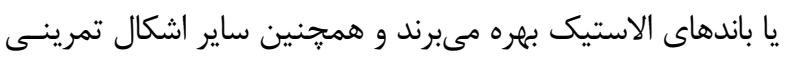

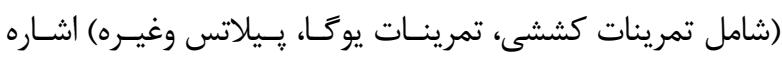
كرد. كاهى خـود از تركيـب ايـن شـيوههـاى تمـرين ( Combine

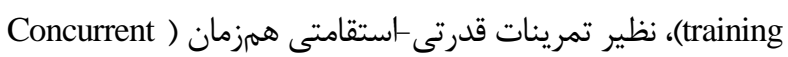
جهــ (Resistance, Endurance exercise بيماران استفاده مىشود. اين شيوههاى تمرين باعث ايجـاد اثـرات متفاوتى بر فعاليـتهـاى اتونوميـك و سـاختارى قلـب ( Cardiac

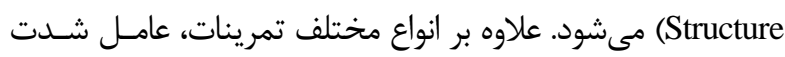

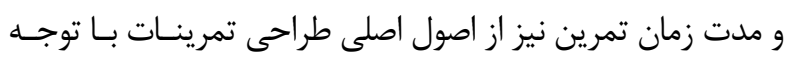
به وضـعيت و شـدت بيمـارى محسـوب مسى شـود (^). Coats و و

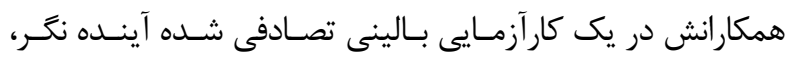

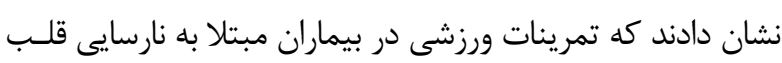

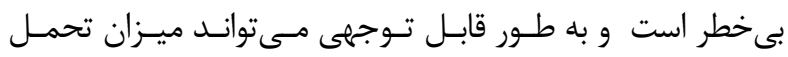

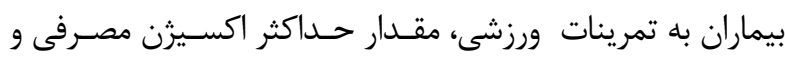
علائم بيمارى نارسايى قلبى نظير فشار خون و تعداد ضـربان قلـب

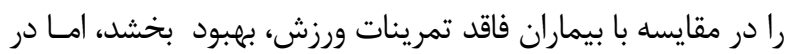
مطالعه خود، ارتباطى بـين LVEF و انجـام تمرينـات در بيمـاران

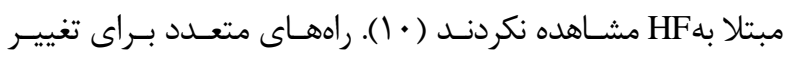

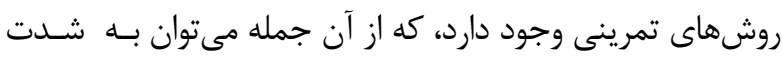

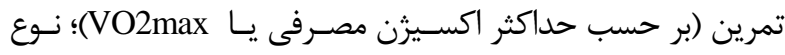

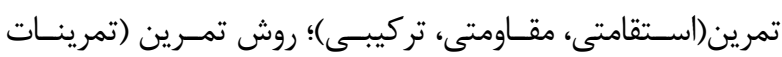

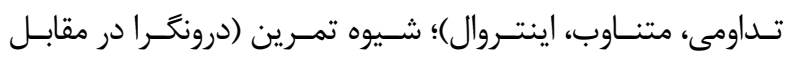




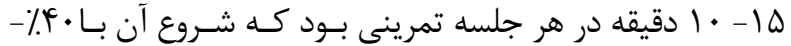

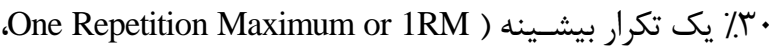
حداكثر بار يا وزنهاى است كه دريك نوبت مىتوان بلند كرد) در دو بـن

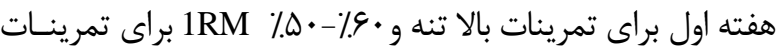
اندام تحتانى با تكرار ها - • ا بار انجام شد. سيس هر دو هفته ه.|

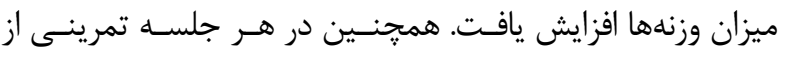

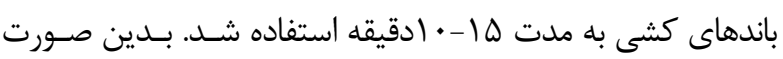
كه در ابتدا از باندهاى با كمترين مقاومت با • • -1 تكـرار وسـيس

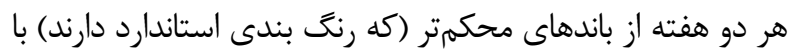

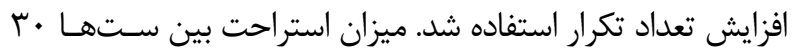

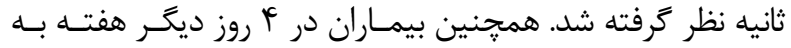

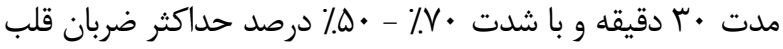

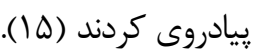
قبل و بعد از ^ هفته تمرينات، اندازه گيرى وزن و قد با اسـتفاده از ترازوى عقربهاى Seca ساخت آلمان و دستخاه قدسـنج اسـتاندارد

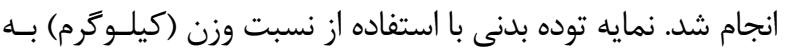
مجذور قد (متر) محاسبه شد. فشار خون (با استفاده از فشار سـنج HEINE ، عقربهاى ،ساخت آلمان)، ضـربان قلـب و ميـزان اشـباع اكسيرن خــون شـريانى بـا دسـتخاه يـالس اكسـى متـرى يرتابـل

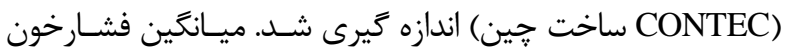
شريانى نيز توسط فرمول زيرمحاسبه شد.

(MAP)=(فشاردياستولى - فشارسيستولى) س/ + فشاردياستولى

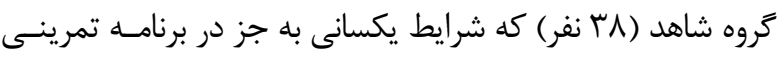
با گروه تجربى داشتند، نيز برنامه معمـول درمـانى خــود را دنبـال

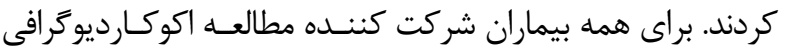

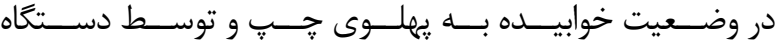
اكوكارديوكراف PHILIPS (مـدل Affiniti 50C سـاخت آمريكـا) انجام شد. از شيوه M-mode براى ارزيـابى قطـر و حجـم يايسان سيستولى و دياستولى و ضـخامت ديـواره بــين بطنسى و ديـواره

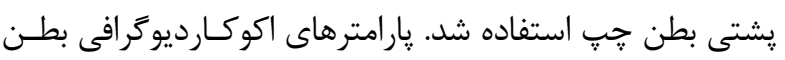
جֶٍ از راهنماى انجمن اكوكارديوكرافى آمريكـا انتخــاب شـدند.

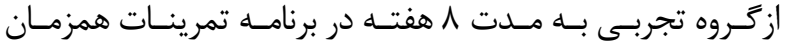
استقامتى - مقاومتى همزمان شركت كردند. مــدت كـل تمرينـات بيش • لها دقيقه درهفته بود. زروه شاهد برنامه دارويى و درمـانى

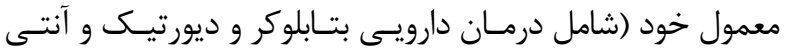
هيبرتانسيون)، رادريافت كردند.

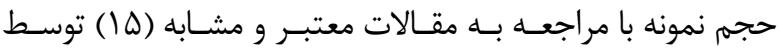

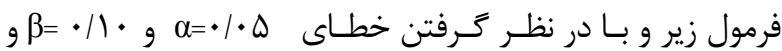
احتمال ريزش • (\% محاسبه شد:

$$
N=\frac{\left(\mathrm{Z} 1-\frac{\alpha}{2}+Z 1-\beta\right) 2\left(S 1^{2}+S 2^{2}\right)}{\left(\mu_{1}-\mu_{2}\right)^{2}}
$$

اين مطالعه يـس از تصـويب كميتـه داورى و خـلاق دانشـاه آزاد

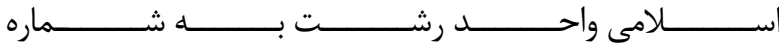
IR.IAU.RASHT.REC.1390.101 و ثبت در سـامانه كارآزمـايى بالينى ايران به شماره IRCT20150531022498N24 انجام شد. يس از ارزيابى اوليه و معرفى بيمار CHF توسط كارديولوزيست و

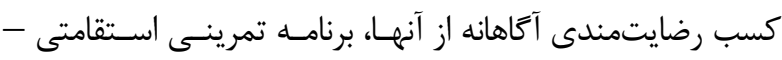

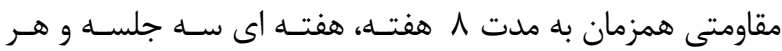

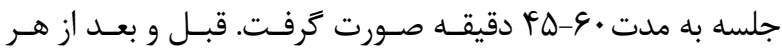
جلسه تمرين حركات نرمشى و كششى جهت گرم كـردن و سـرد كردن به مدت • 1-ه دقيقه انجام شد.

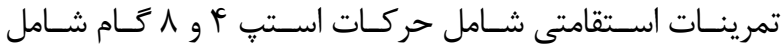
حركـات(March/Walk،V ,A , X, Step ,W Touch to ، Tap back ,Step out Step in،Lunge،Tap front ،Mambo،Side )انجام شد(צ(). شدت تمرينات استقامتى، •V- •• د درصـد ضـربان قلب(حداكثر ضربان قلب توسط فرمول سن - · r محاسبه شـد)

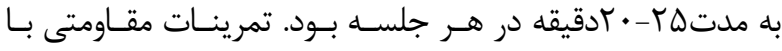

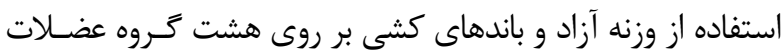
بزرگ بالا تنه و يايين تنه (شامل حركات يـرس سـينه، جلـو يـا،

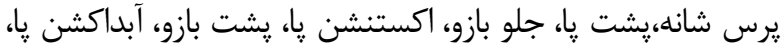

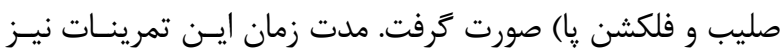

جدول ا. مقاديرطبيعى متغيرهاى اندازه وعملكرد بطن جٍٍ مطابق با جنس دراكو كارديوگرافى دو بعدى

\begin{tabular}{|c|c|c|c|c|}
\hline \multicolumn{2}{|c|}{ 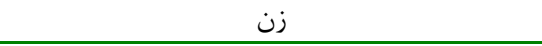 } & \multicolumn{2}{|c|}{ 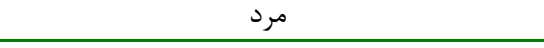 } & \multirow[b]{2}{*}{ 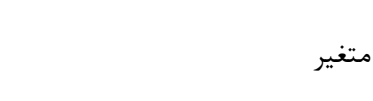 } \\
\hline محدوده دو انحراف معيار & ميانگين土|نحراف معيار & محدوده دو انحراف معيار & ميانكين土|نحراف معيار & \\
\hline$r V / \Lambda-\Delta T / T$ & $r \Delta / \cdot \pm r / \varphi$ & $F Y / \cdot-\Delta N / F$ & $\Delta \cdot / r \pm r / l$ & ابعاددياستوليك(ميلىمتر) \\
\hline TI/S-rF/A & $r \Lambda / r \pm T / r$ & $r \Delta / \cdot-r q / \Lambda$ & $r r / F \pm r / V$ & ابعادسيستوليك(ميلىمتر ) \\
\hline$\Delta F-V F$ & $s 4 \pm \Delta$ & $\Delta r-V T$ & $q r \pm \Delta$ & كسر تخليهاى بطن جֶٍ \\
\hline $9 / 0 \pm 11 / 4$ & $\Lambda / \Delta \pm 1 / \Delta$ & $9 / \pi \pm 1 / 0$ & $\Lambda / \Lambda \pm 1 / \Delta$ & ضخامت ديواره خلفى (ميلىمتر) \\
\hline $4 / \cdot \pm 11 / \pi$ & $\Lambda / r \pm 1 / \Delta$ & $\Lambda / 9 \pm 1 / 9$ & $q / r \pm 1 / 9$ & قطر ســـتوم بـين بطنسى(ميلىمتر) \\
\hline
\end{tabular}


ترتيـب بـا آزمــون t مسـتقل و مـن-ويتنـى U و تغييـرات درون كروهى نيز با استفاده از آزمون t همبسته و و ويلكاكسون انجام شـد.

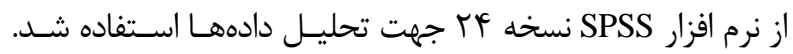
ه • معنى دار در نظر گرفته شد.

\section{يافتهها}

توصيف ويزگَى هاى دموگر افيك، تركيب بدن و علايهم بالينى آزمودنى ها در جدول r نشان داده شده است. با توجه توزيع طبيعى دادهها در شاييروويلك، بررسى تفاوت بين گروهى در ييش آزمون تفاوت معنى دارى بين كروههاى

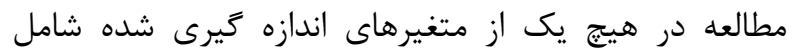
كسرتخليهاى، ضخامت ديواره بين بطنى در دياستول (DIVS: diastolic interventricular septum ديواره خلفى ( posterior wall diastolic thickness or End Diastole Diameter or) (DPW

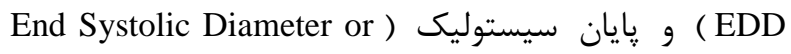
(ESD
مقادير نرمال يارامترهاى اكوكارديوگرافى در جدول ا ارائه شـده

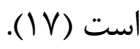

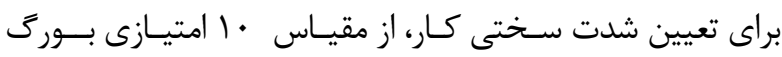
استفاده شد كه در آن نمره صفر به معنى فقدان درك فشار كـار و نمره • ا نشان دهنده حداكثر فشار كارى بود.

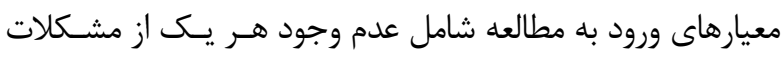

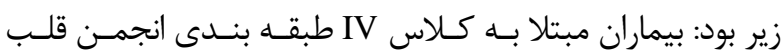

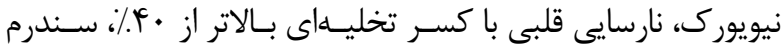

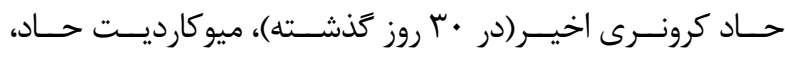

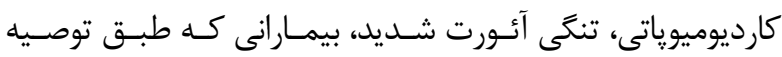
يزشك به دليل مشكل ارتويدى قادر به حركـت نبودنـد، ابـتلا بـهـ

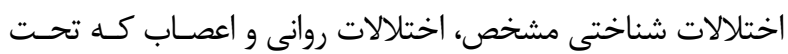
درمان با داروهاى آرامبخش بودند و بيمارانى كه مشـكل كفتـارى وشنوايى داشتند. آمار توصيفى ويزگى آزمودنىها توسط ميـانگين و انحــراف معيـار

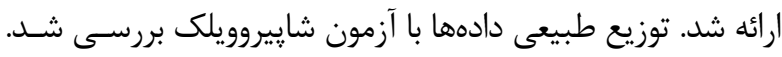

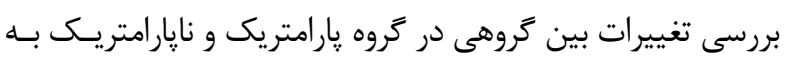

جدول r. توصيف ويزگى هاى دموگرافيك، تر كيب بدن و علائم بالينى بيماران مبتلا به نارسايى قلبى مزمن (تعداد در هر

\begin{tabular}{|c|c|c|}
\hline كروه كنترل & كروه تجربى & متغير \\
\hline$(Y M / V) q$ & $(\mid \Lambda / F) V^{*}$ & جنس (زن) \\
\hline $19 \Delta / q Y \pm r / T V$ & $1 \xi \varphi / 9 \gamma \pm \Delta / \wedge V^{\dagger}$ & قد (سانتى متر) \\
\hline$\vee \uparrow / \wedge ৭ \pm V / V \wedge$ & $V F / V V \pm 11 / 4 q$ & وزن (كيلوكرم) \\
\hline$r V / I V \pm r / \Delta G$ & $r V / \Psi \wedge \pm r / q \Lambda$ & نمايه توده بدن - BMI (كيلوَّرم بر متر مربع) \\
\hline$\varphi N / Y \mid \pm \varepsilon / \Delta \varphi$ & $\varepsilon \vee / \uparrow \Delta \pm \Delta / q)$ & 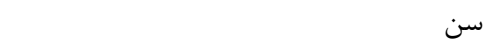 \\
\hline$(q V / F) Y V$ & $(\Lambda / / \varepsilon) \Gamma$ & تنكَى نفس \\
\hline$(q V / F) Y V$ & $(\Lambda F / T) M_{T}$ & درد قفسه سينه \\
\hline$(\cdot) \cdot$ & $(Y r / V) 9$ & 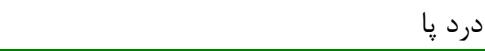 \\
\hline
\end{tabular}

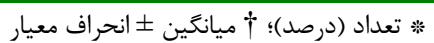

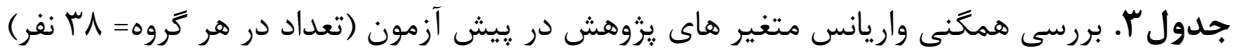

\begin{tabular}{|c|c|c|c|c|c|c|c|}
\hline معنى دارى & درجه آزادى & آماره t & معنى دارى & $\mathbf{F}$ & كنترل & تجربى & \\
\hline.$/ 1 \mathrm{~V}$ & VF & $-1 / \Gamma 4$ & $\cdot / r$ & $1 / 9$. & r & $\Upsilon \backslash / \Delta \wedge \pm \Delta / \Lambda r^{*}$ & كسر تزريقى \\
\hline$\cdot / \Lambda \Lambda$ & $V F$ & $-\cdot / 1 \Delta$ & $\cdot / \cdot \Delta r$ & $r / q$. & $1 \cdot / \mu F \pm \cdot \mid q r$ & $1 \cdot / r r \pm r / q r$ & DIVS \\
\hline $.1 \cdot 9$ & ve & $-1 / 9$ & (r) & $T / \Delta F$ & $q / \wedge \varepsilon \pm \cdot / \Delta T$ & $q / \mathcal{F} \wedge \pm I / r\}$ & DPW \\
\hline.$/ 1$ & $V v^{c}$ & س & ع ع/. & •/AK & $\Delta r / \Lambda F \pm F / V G$ & $\Delta F / V \varphi \pm \Delta / \& \varepsilon$ & EDD \\
\hline $.1 \cdot 4$ & $V F$ & $1 / 19$ & $.19 \mathrm{~V}$ &.$/ 11$ & $\psi \varepsilon / \Delta F \pm \Delta / F q$ & $\mid q q / \cdot \pm q q / \cdot \cdot$ & ESD \\
\hline$\cdot 1 \cdot V$ & VF & $-1 / V F$ & . 194 & $.1 \cdot \cdot 4$ & $119 / \wedge \varepsilon \pm 1 \Delta / 1 \vee$ & $|1 \% / \varepsilon \wedge \pm| F / 9 \varepsilon$ & فشار خون سيستول \\
\hline .111 & $V F$ & $-1 / 09$ & $\cdot / 11$ & I/VD & $99 / 97 \pm 9 / 19$ & $G K / F Y \pm 1 \cdot / r$. & فشار خون دياستول \\
\hline.$/ 1 F$ & $V F$ & $-1 / \Delta 9$ & $\cdot|4|$ & $\cdot 199$ & $q r / F F \pm \mid r / \cdot 1$ & $\Lambda \Lambda / F \vee \pm \| / G \mathcal{F}$ & ضربان قلب \\
\hline .1 .9 & $V F$ & $-1 / 9$ & $\cdot / T V$ & M & $\Lambda F / 9 \cdot \pm \Lambda / 99$ & $\Lambda \cdot / / \vee \pm \| / / 4$ & ميانكين فشار شريانى \\
\hline
\end{tabular}

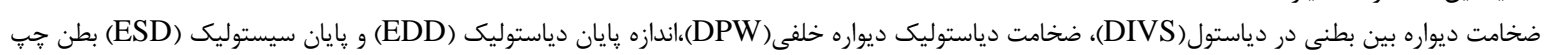




\begin{tabular}{|c|c|c|c|c|c|c|c|}
\hline \multicolumn{2}{|c|}{ تغييرات درون گروهى } & \multicolumn{2}{|c|}{ تغييرات بين گروهى } & \multirow[t]{2}{*}{ 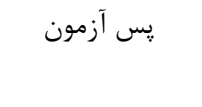 } & \multirow[t]{2}{*}{ ي بيش آزمون } & \multirow[t]{2}{*}{ تروه } & \multirow[t]{2}{*}{ متغير } \\
\hline معنى دارى & $\mathrm{t}$ & معنى دارى & $\mathrm{t}$ & & & & \\
\hline$\cdot / \cdots *$ & $-9 / \cdot 9$ & $\cdot 1 \cdot{ }^{\text {萗絭 }}$ & N/FF & $\Gamma \wedge / \Lambda \Delta \pm \varepsilon / \Gamma \Lambda$ & $r / / \Delta \Lambda \pm \Delta / \wedge \mu^{\dagger}$ & تجربى & كسر تخليهاى(درصد) \\
\hline$\cdot / \cdot 1$ & I/VV & & & $r \Gamma / \Lambda \pm F / \Delta r$ & 促 & كنترل & \\
\hline$\cdot / \cdot *$ & $1 \cdot 11$ & $\cdot 1 . .^{* * *}$ & $-1 \cdot / \Delta F$ & $r q / \Delta V \pm r / V$. & $\varepsilon q / \cdot \cdot \pm \varepsilon / \cdot \cdot$ & 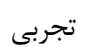 & حجم پِايان سيستول (ميلى ليتر) \\
\hline$\cdot / \cdot \wedge$ & $-1 / \wedge$ & & & $\vee V / \cdot V \pm \Delta / ৭ \varphi$ & $\kappa \varepsilon / \Delta Y \pm \Delta / r V$ & كنترل & \\
\hline$\cdot / *^{*}$ & N/YG & $\cdot 1 \cdot{ }^{\text {*** }}$ & $-\Lambda / r \cdot$ & $\varphi \in / V \mid \pm \Delta / r \Delta$ & $\Delta F / V \& \pm \Delta / F \varepsilon$ & 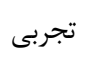 & حجم پايان دياستول(ميلى ليتر) \\
\hline$\cdot / 14$ & $-1 / \omega$ & & & $\Delta r / V I \pm \Delta / I r$ & $\Delta r / \Lambda F \pm F / V q$ & كنترل & \\
\hline$\cdot \operatorname{lAt}$ & $\cdot / T$ & $\cdot 19 \Lambda$ & $-\cdot|4|$ & $1 \cdot / 14 \pm \cdot / q$ & $1 \cdot / r F \pm r / q r$ & 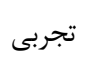 & DIVS \\
\hline .119 & $-1 / 4$ & & & $1 \cdot / \mathcal{E V} \pm \cdot / V q$ & $1 \cdot / K F \pm \cdot / 9 r$ & كنترل & \\
\hline$\cdot / \cdot \varphi^{*}$ & $-T / M$ &.$/ 14$ & $1 / \Delta F$ & $1 \cdot 1 \cdot r \pm 1 / r T$ & $q / \uparrow \wedge \pm 1 / r r$ & 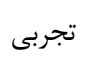 & PWD \\
\hline$\cdot / \cdot 1$ & $-1 / V \wedge$ & & & $1 \cdot / \cdot r \pm \cdot / \mathscr{V V}$ & $q / \Lambda 9 \pm \cdot / D T$ & كنترل & \\
\hline$\cdot / \cdots *$ & $F / \Delta r$ & $\cdot 1 \cdot{ }^{\text {*** }}$ & $-\varphi / \Delta r$ & $\Delta T / V \& \pm \Delta / \Psi \varepsilon$ & $\Delta F / V \& \pm \Delta / F \varepsilon$ & 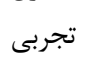 & EDD \\
\hline$\cdot / \cdot 1$ & $-1 / 1$ & & & $\Delta r / V I \pm \Delta / I r$ & $\Delta r / \Lambda F \pm F / V \varepsilon$ & كنترل & \\
\hline$\cdot 1 \cdot *^{*}$ & $r / \cdot r$ & $\cdot 1 \cdot .^{\text {*** }}$ & $-r / \cdot r$ & $\varphi \varepsilon / V \mid \pm \Delta / 9 \Lambda$ & $\mid q q / \cdot \cdot \pm \varepsilon / \cdots$ & 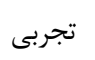 & ESD \\
\hline$\cdot / 1 \mathrm{~V}$ & $-1 / T V$ & & & $\mid \vee V / \cdot \Delta \pm \varepsilon / \cdot q$ & $\forall \varepsilon / \Delta \uparrow \pm \Delta / F \psi$ & 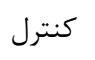 & \\
\hline$\cdot / 48$ & $-1 / 11$ & $\cdot 1 \Delta \Delta$ & $\cdot 109$ & $\||\varepsilon / \Gamma| \pm V / \wedge \Delta$ & $\|r / q \Lambda \pm\| F / 9 \varphi$ & 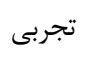 & فشار خون سيستول (ميلى متر جيوه) \\
\hline$\cdot / V$ & $-\cdot / r V$ & & & $\mid r \cdot 19 \Delta \pm 1 r / T \varphi$ & $119 / \wedge \varepsilon \pm 10 / 1 \vee$ & كنترل & \\
\hline 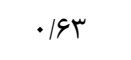 & $\cdot / 4 V$ & $\cdot / 4$ & $-\cdot / \Lambda r$ & $G \Psi / F T \pm \varepsilon / \wedge D$ & 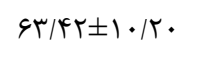 & 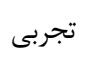 & فشار خون دياستول (ميلى متر جيوه) \\
\hline$\cdot / F \Delta$ & $-\cdot / V 8$ & & & $\checkmark V / \wedge ৭ \pm q / \cdot \Delta$ & $98 / 9 \vee \pm 9 / 19$ & كنترل & \\
\hline$\cdot / \cdot \cdot)^{*}$ & $r / 90$ & $\cdot 1 \cdot \cdot)^{\text {䔞 }}$ & $-r / \Delta 9$ & $\Lambda \cdot / r \varepsilon \pm V / q \vee$ & $\Lambda \Lambda / F \vee \pm 11 / G \uparrow$ & 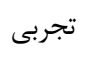 & ضربان قلب (ضربه در دقيقه) \\
\hline$\cdot / 4 t$ & $-1 / T r$ & & & $q F / V I \pm \mid F / \Delta T$ & $q Y / F Y \pm \mid r / \cdot 1$ & كنترل & \\
\hline$\cdot \mid A F$ & $-\cdot 119$ & $\cdot|\Lambda|$ & $-\cdot / T F$ & $\Lambda \cdot \mid \Delta r \pm 9 / \Delta \Delta$ & $\Lambda \cdot / 1 \vee \pm \| / / \mathrm{F}$ & 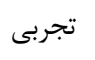 & ميانگين فشار شريانى \\
\hline$\cdot / 49$ & $-\cdot 19 \Lambda$ & & & 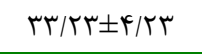 & 低 & كنترل & \\
\hline
\end{tabular}

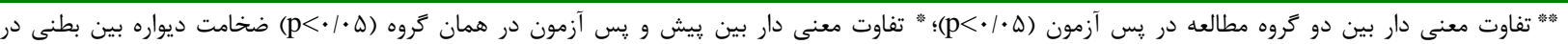

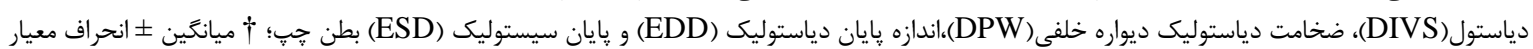

كنترل نيز تغيير بارزى در هيج از متغيرهاى اندازهيرى

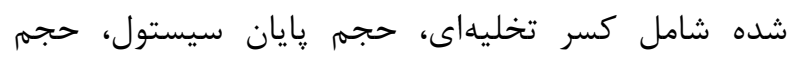

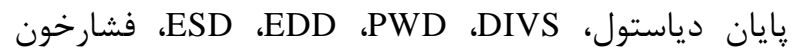
سيستول، فشار خون دياستول، ضربان قلب و ميانگين فشار

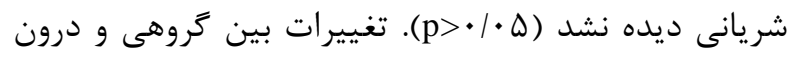

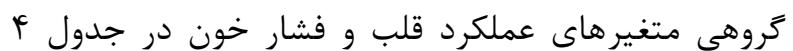
ارائه شده است.

\section{بحث}

هـــف از مطالعـه حاضــ، تعيـين اثـر تمرينــات اسـتقامتى و مقاومتى همزمان در ساختار و عملكرد قلب و فشار خون بيمار

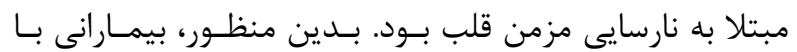

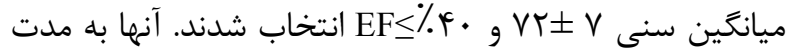

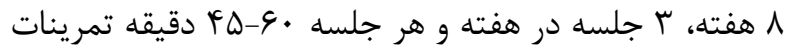

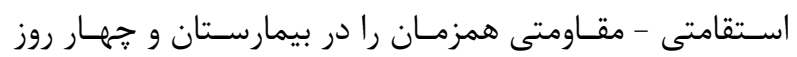

ضربان قلب و ميانكين فشار وجود نداشت (ه•/•)

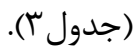

بعد از حذف تاثير ييش آزمون، نتايج آزمون t مستقل

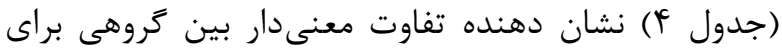
متغيرهاى كسر تخليهاى، حجم پايان سيستول، حجم يايان

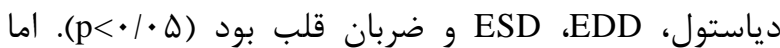
تفاوت بارزى بين دو گروه براى متغيرهاى DIVS، PWD،

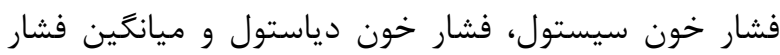

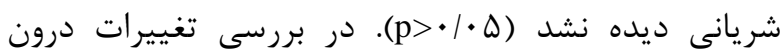
كروهى در كروه تجربى، افزايش معنى دار در كسر تخليداى و حجم پايان سيستولى و كاهش معنى دار در حجم رايايان

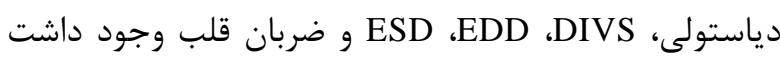

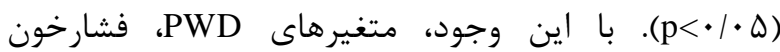
سيستول، فشار خون دياستول و ميانگين فشار شريانى تغيير

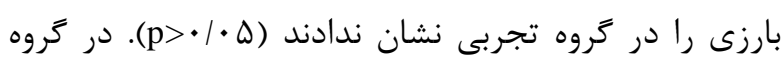


فشارخون سيستولى در هر دو گروه با تمـرين و بـدون تمـرين

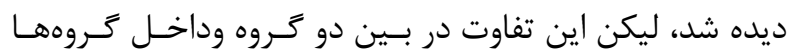

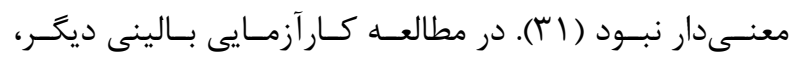
دهكردى و همكارانش (ه| • (Y) تأثيرتمرينات ورزشى بركيفيت

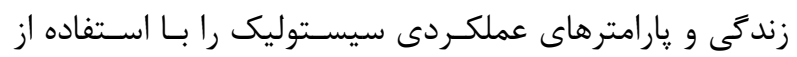
اكو كارديو گرافى دربيماران مبتلا به نارسايى مزمن قلبـى مــورد

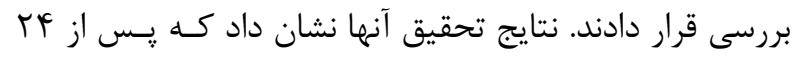
هفته برنامه تمرينى، تفــاوت معنسى دار در قطـر سيسـتوليكى و و

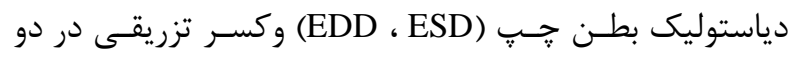

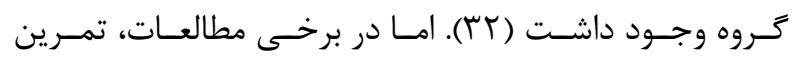
مقاومتى، اثرى بر بازسازى بطن جٍٍ (LV) نداشـت؛ در واقـع،

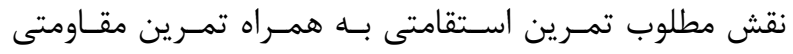

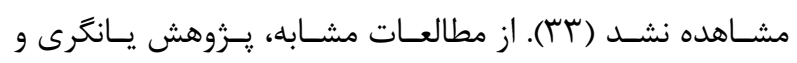

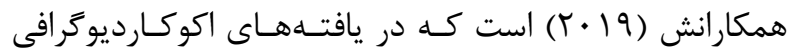

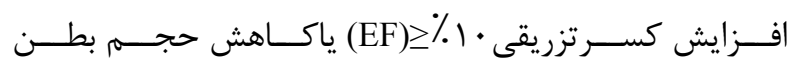

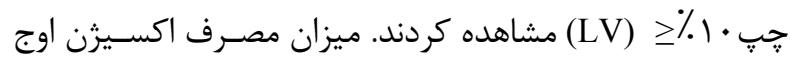

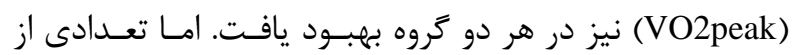
بيماران، EF يايينتر و بطن جٍِ بزرگترى داشتند، ليكن اين

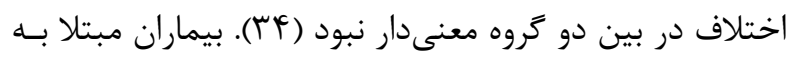

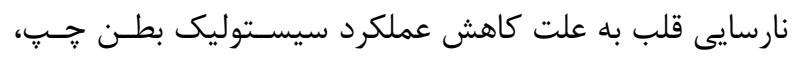

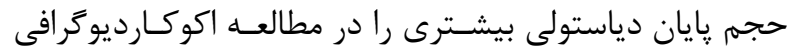

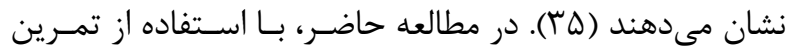

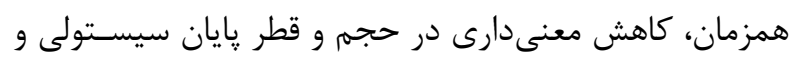

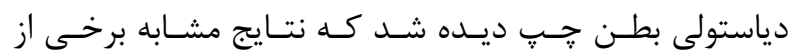

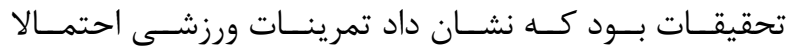

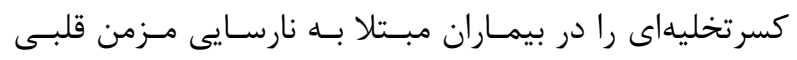

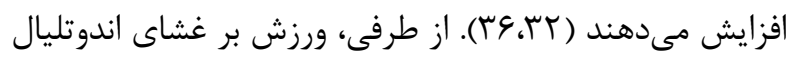

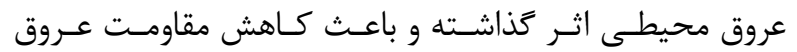
محيطى مىشود. در نتيجه، با كاهش ميزان استرس بر ديـواره

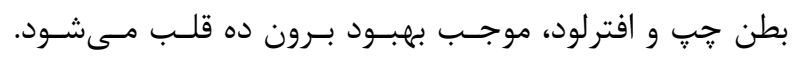
مطالعات قبلى كه به مدت طولانى ترى انجام شد از اين يافته-

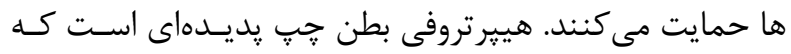

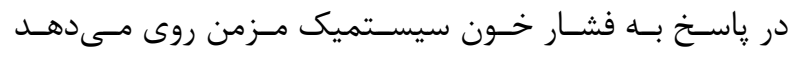

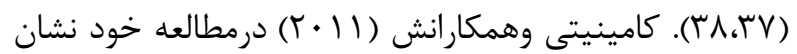
دادند كه تمرين تايجى همراه باتمرينـات اسـتقامتى مسى توانـد بيشتر ازتمرينات استقامتى به تنهايى، موثر باشد. اين محققين

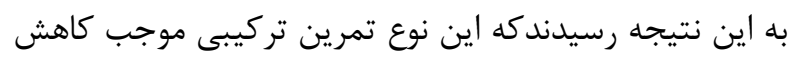

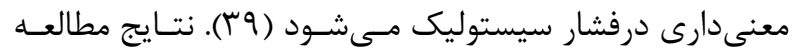

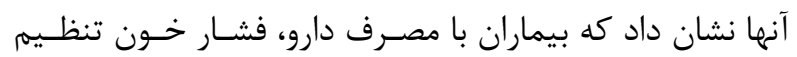

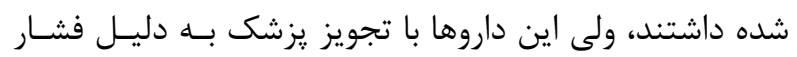

باقيمانده هفته را به يياده روى يرداختند. نتايج حاصـل از ايـن يزوهش نشان داد كه اين برنامه تمرينى موجب بهبود شـاخص

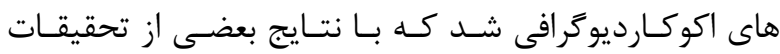

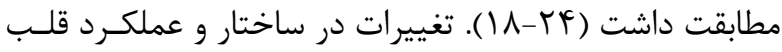

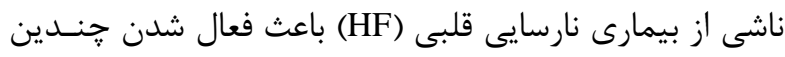

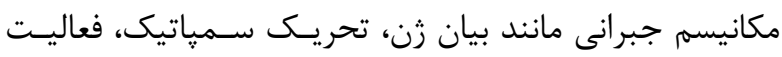

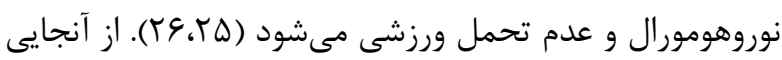
كه اين فرآيند مورفولوزيك قبل از شروع علائم آغاز مسىشـود، دستورالعملهاى اخير براى بيماران نارسايى قلب، تاكيد ويـزّهـ

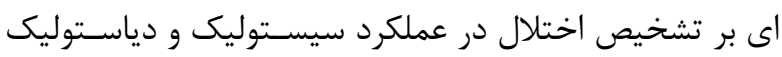
بطن جِّ اين بيماران دارند. براى اندازهگيرى عملكرد بطنسى و

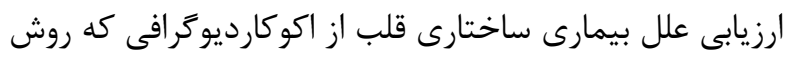

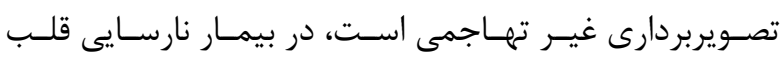

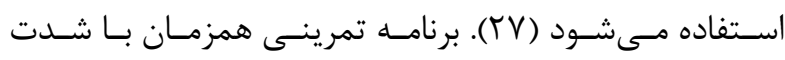

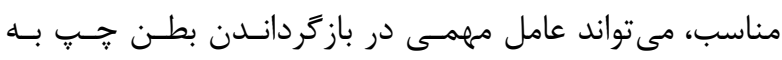
حالت طبيعى و بهبــود ظرفيـت اسـتقامتى در بيمـاران دجــــار نارسايى قلبى مزمن باشد (Y^). تمرينات منظمه، ظرفيت انجـام كار را افزايش داده و نشان مى مدهد كه ظرفيت تمرينى درميـان

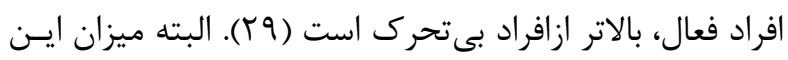
تاثيرات به شدت تمرينات نيز بستخى دارد، به نحوى كه نشـان

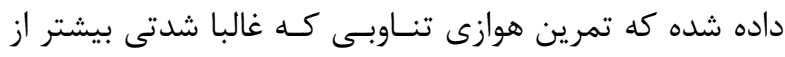

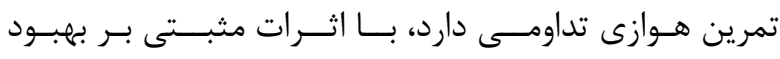

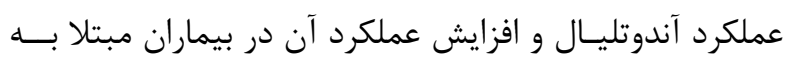

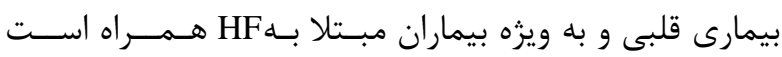

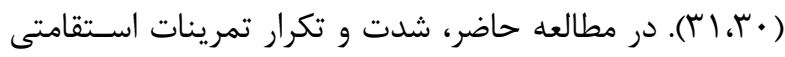
و مقاومتى، هر دو هفته بهطور تناوبى اضافه شد كه اين امر بـا

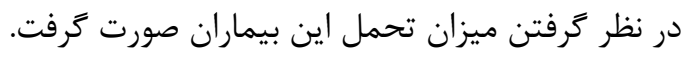

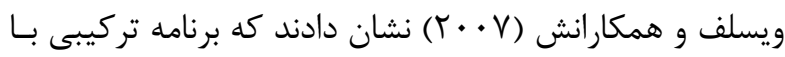
شدت مناسب مى تواند عامل مهمى در بهببودى عملكــرد بطـن

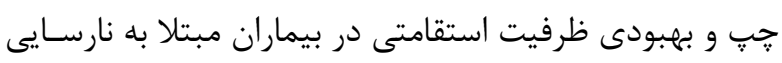

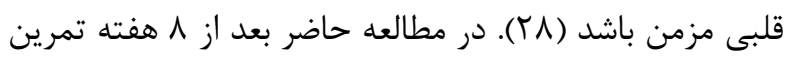

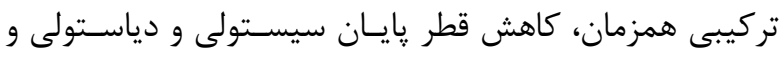

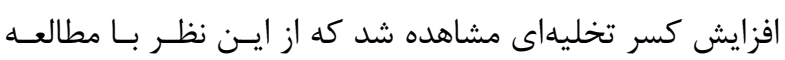

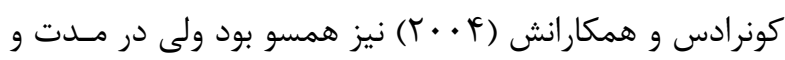

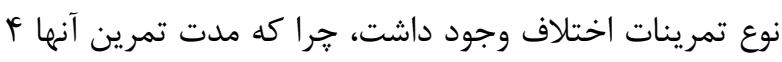

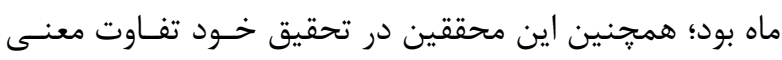

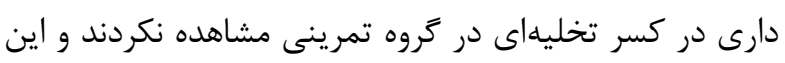

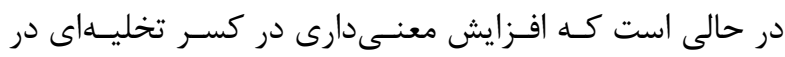
مطالعه ما مشاهده شـد. همجنــــن كـونرادس و همكـارانش بــا

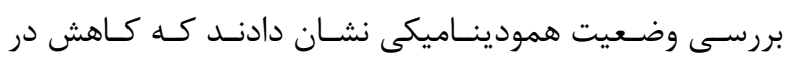




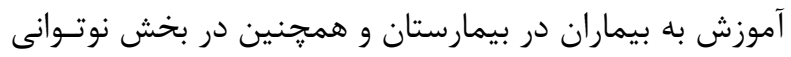

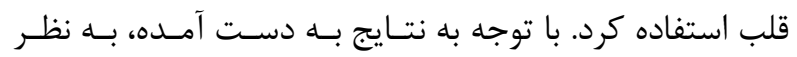

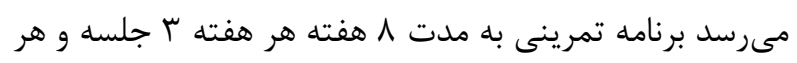

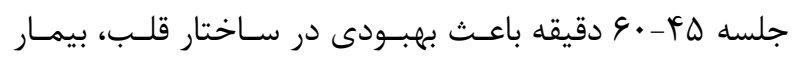

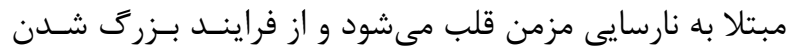

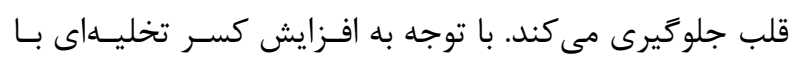

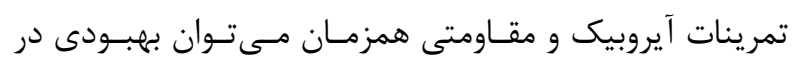

$$
\begin{aligned}
& \text { عملكرد انقباضى قلب را نتيجه كرفت }
\end{aligned}
$$

$$
\text { تشكر و قدردانى }
$$

از رياست بيمارستان، مـديريت يرسـتارى، كاركنـان كلينيـك

تخصصى مركز آموزشى درمانى دكتر حشمت رشت و و بيمـاران

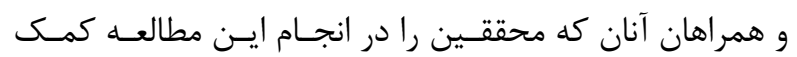

$$
\text { كردند، تقدير و سياس بهعمل مى آيد. }
$$

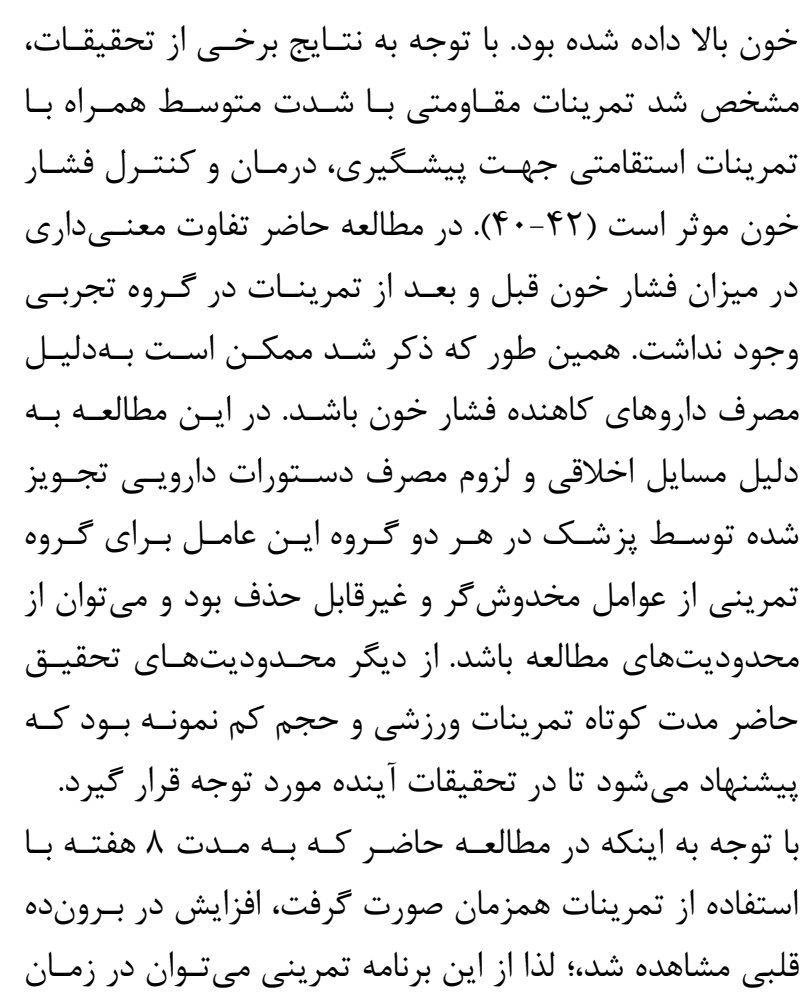

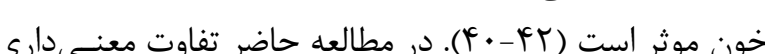

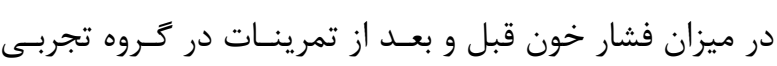

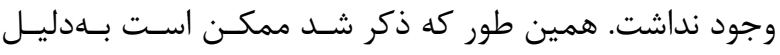

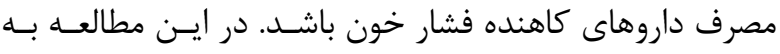

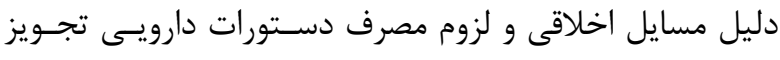

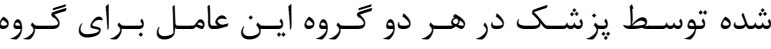

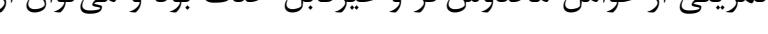

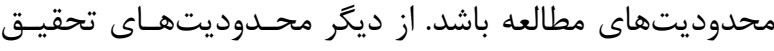

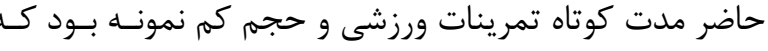

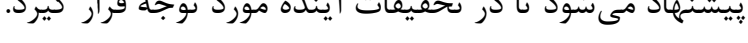

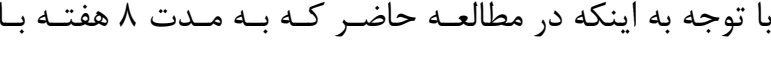

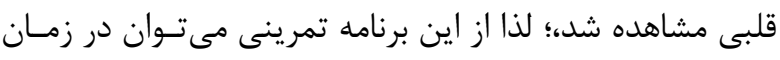

\section{REFERENCES}

1. Benjamin Ivor, Griggs Robert, Wing Edward, Fitz J Gregory, Eds. Cecil essentials of medicine. Gharoni M, translator. Tehran: Arjmand Pub; 2016. [In Persian]

2. McMurray JJ, Pfeffer MA. Heart failure. Lancet 2005; 365: 1877-89.

3. Gardner RS, McDonagh TA, Walker NL, Eds. Oxford specialist handbooks in cardiology heart failure. London: Oxford Medical; 2014.

4. Adamopoulos S, Parissis J, Kroupis C. Physical training reduces peripheral markers of inflammation in patients with chronic heart failure. Eur Heart J 2001; 22: 791-97.

5. Giannuzzi P, Temporelli PL, Corra U. Antiremodeling effect of long-term exercise training in patients with stable chronic heart failure: results of the exercise in left ventricular dysfunction and chronic heart failure (ELVD-CHF) trial. Circulation 2003; 108: 554-59.

6. Gielen S, Adams V, Mobius-Winkler S. Antiinflammatory effects of exercise training in the skeletal muscle of patients with chronic heart failure. J Am Coll Cardiol 2003; 42: 861-68.

7. Stanek B, Frey B, Hulsmann M. Prognostic evaluation of neurohumoral plasma levels before and during beta-blocker therapy in advanced left ventricular dysfunction. J Am Coll Cardiol 2001; 38: 436-42.

8. Pollock ML, Gaesser G, Butcher JD, Després JP, Dishman RK, Franklin BA, et al. The recommended quantity and quality of exercise for developing and maintaining cardiorespiratory and muscular fitness, and flexibility in healthy adults. Med Sci Sports Exerc 1998; 30: 975-91.

9. Coats AJ, Adamopoulos S, Meyer TE, Conway J, Sleight P. Effects of physical training in chronic heart failure. Lancet 1990; 335: 63-66.

10. Ponikowski P, Voors AA, Anker SD, Bueno H, Cleland JG, Coats AJ, et al. 2016 ESC Guidelines for the diagnosis and treatment of acute and chronic heart failure: The Task Force for the diagnosis and treatment of acute and chronic heart failure of the European Society of Cardiology (ESC). Developed with the special contribution of the Heart Failure Association (HFA) of the ESC. Eur J Heart Fail 2016; 18: 891-75.

11. Abela M. Exercise training in heart failure. Curr Cardiol Rep 2018; 1-6.

12. Braith RW and Beck DT. Resistance exercise: training adaptations and developing a safe exercise prescription. Heart Fail Rev 2008; 13: 69-79.

13. Williams M, Haskell W, Ades P. Resistance exercise in individuals with and without cardiovascular disease. A scientific statement from the American Heart Association Council on Clinical Cardiology and Council on Nutrition, Physical Activity and Metabolism. Circulation 2007; 116: 572-584. 
14. Arthur HM. Effects of aerobic vs. combined aerobic-strength training on 1-year, post-cardiac rehabilitation outcomes in women after a cardiac event. J Rehabil Med. 2007; 39, 730-5.

15. Gary RA, Cress ME, Higgins MK, Smith AL, Dunbar SB. Combined aerobic and resistance exercise program improves task performance in patients with heart failure. Arch Phys Med Rehab 2011; 92:1371-81

16. Khan AA, Us-Saba N, Khan MU. Aerobic exercises in heart failure-a review. Pakistan Journal of Rehabilitation. 2012; 1: 21-26.

17.Lang RM, Badano LP, Mor-Avi V, Afilalo J, Armstrong A, Ernande L, et al. Recommendations for cardiac chamber quantification by echocardiography in adults: an update from the American Society of Echocardiography and the European Association of Cardiovascular Imaging. J Am Soc Echocardiogr 2015; 28:1-39.e14

18. Hambrecht R, Wolf A, Gielen S, Linke A, Hofer J, Erbs S, et al. Effect of exercise on coronary endothelial function in patients with coronary artery disease. N Engl J Med 2000; 342: 454-60.

19. Giannuzzi P, Temporelli PL, Corra U, Gattone M, Giordano A, Tavazzi L. Attenuation of unfavorable remodeling by exercise training in postinfarction patients with left ventricular dysfunction: results of the exercise in left ventricular dysfunction (ELVD) trial. Circulation 1997; 96: 1790-7.

20. Dubach P, Myers J, Dziekan G, Goebbels U, Reinhart W, Vogt P, et al. Effect of exercise training on myocardial remodeling in patients with reduced left ventricular function after myocardial infarction. Circulation 1997; 95: $2060-7$.

21. Smart N, Haluska B, Jeffriess L, Marwick TH. Exercise training in systolic and diastolic dysfunction: effects on cardiac function, functional capacity, and quality of life. Am Heart J 2007; 153: 530-6.

22. Ehsani AA, Biello DR, Schultz J, Sobel BE, Holloszy JO. Improvement of left ventricular contractile function by exercise training in patients with coronary artery disease. Circulation 1986; 74: 350-8.

23. Froelicher VF, Ed. Exercise and the Heart. Philadelphia, PA: W B Saunders Co; 2000.

24. Levinger I, Bronks R, Cody DV, Linton I, Davie A. The effect of resistance training on left ventricular function and structure of patients with chronic heart failure. Int J Cardiol 2005; 105: 159-63.

25. Ahmad T, Fiuzat M, Felker GM, O'connor C. Novel biomarkers in chronic heart failure. Nature Reviews Cardiology 2012; 9:347.

26. Kränkel N, Adams V, Gielen S, Linke A, Erbs S, Schuler G, et al. Differential gene expression in skeletal muscle after induction of heart failure: impact of cytokines on protein phosphatase 2A expression. Mol Genet Metab 2003; 80:262-71.

27. Hunt SA, Abraham WT, Chin MH. ACC/AHA 2005 Guideline Update for the Diagnosis and Management of Chronic Heart Failure in the Adult: a report of the American College of Cardiology/American Heart Association Task Force on Practice Guidelines (Writing Committee to Update the 2001 Guidelines for the Evaluation and Management of Heart Failure): developed in collaboration with the American College of Chest Physicians and the International Society for Heart and Lung Transplantation: endorsed by the Heart Rhythm Society. Circulation 2005; 112:e154-e235.

28. Wisløff U, Stoylen A, Loennechen JP, Bruvold M, Rognmo O, Haram PM, et al. Superior cardiovascular effect of aerobic interval training versus moderate continuous training in heart failure patients. Circulation 2007; 115:3086-3094.

29. Berra K, Hamm LF, Kavanagh T, Eds. AACVPR cardiac rehabilitation resource manual. Champaign: Human Kinetics; 2006.

30. Cockburn J, Blows L, Cohen A, Holmberg S, Hyde J, Lewis M, et al. Acute ischemic comp lications of PCI and CABG: who should cover whom for coronary revascularization? J Interv Cardiol 2013; 26: 372-377.

31. Dendale P, Berger J, Hansen D, Vaes J, Benit E, Weymans M. Cardiac rehabilitation reduces the rate of major adverse cardiac events after percutaneous coronary intervention. Eur J Cardiovasc Nurs 2010; 4: 113-116.

32. Dehkordi AH, Far AK. Effect of exercise training on the quality of life and echocardiography parameter of systolic function in patients with chronic heart failure: a randomized trial. Asian J Sports Med 2015; 6: 33-6

33. Skidmore BL, Jones MT, Blegen M, Matthews TD. Acute effects of three different circuit weight training protocols on blood lactate, heart rate, and rating of perceived exertion in recreationally active women. J Sports Sci Med 2012; $11: 660-668$.

34. Yanagi H, Nakanishi M, Konishi H, Yamada S, Fukui N, Kitagaki K, et al. Effect of exercise training in heart failure patients without echocardiographic response to cardiac resynchronization therapy. Cir Rep 2019; 1: 55-60.

35. Verdiani V, Ognibene A, Rutili MS, Lombardo C, Bacci F, Terreni A, et al. NT-ProBNP reduction percentage during hospital stay predicts long-term mortality and readmission in heart failure patients. J Cardiovasc Med 2008; 9: 694-9. 
36. van Tol BA, Huijsmans RJ, Kroon DW, Schothorst M, Kwakkel G. Effects of exercise training on cardiac performance, exercise capacity and quality of life in patients with heart failure: a meta-analysis. Eur J Heart Fail 2006; $8: 841-50$.

37. Devereux RB, Alonso DR, Lutas EM, Gottlieb GJ, Campo E, Sachs I, et al. Echocardiographic assessment of left ventricular hypertrophy: comparison to necropsy findings. Am J Cardiol 1986; 57: 450- 8.

38. Ganau A, Devereux RB, Roman MJ, de SG, Pickering TG, Saba PS, et al. Patterns of left ventricular hypertrophy and geometric remodeling in essential hypertension. J Am Coll Cardiol 1992; 19: 1550-8.

39. Caminiti G, Volterrani M, Marazzi G, Cerrito A, Massaro R, Arisi A, et al. Tai chi enhances the effects of endurance training in the rehabilitation of elderly patients with chronic heart failure. Rehabil Res Pract $2011 ; 2011$.

40. Pollock ML, Franklin BA, Balady GJ, Chaitman BL, Fleg JL, Fletcher B, et al. AHA Science Advisory: resistance exercise in individuals with and without cardiovascular disease: benefits, rationale, safety, and prescription: an advisory from the Committee on Exercise, Rehabilitation, and Prevention, Council on Clinical Cardiology, American Heart Association; Position paper endorsed by the American College of Sports Medicine. Circulation 2000; 101: 828-833

41. Pescatello LS, Franklin BA, Fagard R, Farquhar WB, Kelley GA, Ray CA. American College of Sports Medicine position stand. Exercise and hypertension. Med Sci Sports Exerc 2004; 36: 533-553.

42. Dor-Haim H, Barak S, Horowitz M, Yaakobi E, Katzburg S, Swissa M, et al. Correction: improvement in cardiac dysfunction with a novel circuit training method combining simultaneous aerobic-resistance exercises. A randomized trial. PLoS One 2018; 13: 1-14. 